\title{
SOCIAL COGNITIVE THEORY AND PREMARITAL SEX AMONG ADOLESCENTS IN YOGYAKARTA
}

\author{
Sitti Nur Djannah \\ Department of Public Health Science, Ahmad Dahlan University
}

\begin{abstract}
BACKGROUND: Globalization and modernization seemed to have profound impact on the behavior of teenagers, especially sexual behavior. Social-cognitive theory proposed by Albert Bandura is a theoretical perspective that focuses on learning by observing others. One of the assumptions in the social-cognitive theory puts that learners can acquire new behaviors and knowledge by simply observing a model. A model is a person who demonstrates behavior for someone else. A peer group of an adolescent may function as this model. This study aimed to explain the role of peer group and mass-media in premarital sex among adolescents in Yogyakarta.

SUBJECT AND METHODS: This was a cross-sectional study conducted in Yogyakarta, with quantitative and qualitative methods of data collection. A sample of 47 teenagers was selected from Turonggo Wiro Budoyo community, Wirobrajan, Yogyakarta. The dependent variable was premarital sex. The independent variables were coercive initiative, exposure to pornographic mass-media, and reference to peer group model. The peer group under study was that with any member ever had experienced premarital sex. A set of questionnaire was developed and pre-tested to measure the study variables. Bivariate analysis with Odds Ratio and ChiSquare was used to analyze the data.

RESULTS: Incidence of premarital sex showed positive and strong association with coercive initiative $(\mathrm{OR}=20.30 ; 95 \% \mathrm{CI}=2.21$ to 186.00 ; $\mathrm{p}<0.001)$, exposure to pornographic mass-media $(\mathrm{OR}=3.88 ; 95 \% \mathrm{CI}=$ 0.09 to $21.70 ; p=0.105)$, and reference to peer group model $(O R=6.00$; 95\% CI=1.06 to $33.95 ; \mathrm{p}=0.028$ ).

CONCLUSION: Coercive initiative, exposure to pornographic massmedia, and reference to peer group model, are risk factors premarital sex among adolescents in Yogyakarta. This study supports Albert Bandura's social-cognitive theory, which emphasizes the role of peer group that functions as a model for adolescents to observe and learn about premarital sex as a new behavior.
\end{abstract}

Keywords: social-cognitive theory, peer group, model, premarital sex, adolescent 